\title{
Depression and ability to work after vestibular schwannoma surgery: a nationwide registry-based matched cohort study on antidepressants, sedatives, and sick leave
}

\author{
Erik Thurin ${ }^{1,2}$ - Petter Förander ${ }^{3,4} \cdot$ Jiri Bartek $\mathrm{Jr}^{3,4,5} \cdot$ Sasha Gulati ${ }^{6,7} \cdot$ Isabelle Rydén ${ }^{1}$. Anja Smits ${ }^{1,8}$. \\ Göran Hesselager $^{9} \cdot \varnothing_{\text {yvind Salvesen }}{ }^{10} \cdot$ Asgeir Store Jakola $^{1,6,11}$
}

Received: 4 March 2021 / Accepted: 22 April 2021

(c) The Author(s) 2021

\begin{abstract}
Background In patients with vestibular schwannomas (VS), tumor control is often achieved, and life expectancy is relatively good. The main risks of surgical treatment are hearing loss and facial nerve function. The occurrence of mood and sleeping disorders in relation to surgery is an important aspect of health that has rarely been studied. Similarly, only limited data exist on the rate of sick leave for patients with VS. In this nationwide registry-based study, we define the use of antidepressants and sedatives and the sick leave pattern before and after VS surgery.

Methods Adult patients with histopathologically verified VS were identified in the Swedish Brain Tumor Registry (SBTR) and clinical data were linked to relevant national registries after assigning five matched controls to each patient. We studied patterns of dispensed antidepressants and sedative drugs as well as patterns of sick leave compared to respective controls at 2 years before and 2 years following surgery.

Results We identified 333 patients and 1662 matched controls. The rate of antidepressant use was similar between patients and controls 2 years before surgery (6.0\% vs $6.3 \%)$ and 2 years after surgery $(10.1 \%$ vs $7.5 \%)$. The rate of sedative use was also similar 2 years before surgery ( $3.9 \%$ vs $4.3 \%)$ and 2 years after surgery ( $4.8 \%$ vs $5.3 \%)$. The rate of sick leave was similar at baseline between patients and controls, but at 2 years after surgery, $75 \%$ of patients vs $88 \%$ of controls $(p<0.01)$ had no registered sick leave. Long-term sick leave after surgery was predicted by use of sedatives (OR 0.60, 95\% CI 0.38-0.94, $p=0.03$ ), more preoperative sick leave (OR 0.91, 95\% CI 0.89-0.93, $p<0.001)$, and new-onset neurological deficits after surgery (OR $0.42,95 \%$ CI $0.24-0.76, p=0.004$ ).

Conclusion This nationwide study shows no significant differences in the use of antidepressants and sedatives between patients and controls, while the rate of postoperative sick leave was higher in patients than in controls after VS surgery. Our findings underpin the importance of avoiding surgical sequelae and facilitating return to normal professional life.
\end{abstract}

Keywords Vestibular schwannoma $\cdot$ Neurosurgery $\cdot$ Antidepressants $\cdot$ Sick leave

\begin{tabular}{|c|c|}
\hline Abbre & iations \\
\hline ATC & Anatomic therapeutic chemical \\
\hline MDD & Major depressive disorder \\
\hline RT & Radiotherapy \\
\hline
\end{tabular}

This article is part of the Topical Collection on TumorSchwannoma

Øyvind Salvesen and Asgeir Store Jakola shared last authorship and contributed equally.

Erik Thurin

erik.thurin@neuro.gu.se

Extended author information available on the last page of the article
RTW Return to work

SBTR Swedish brain tumor registry

SRS Stereotactic radiosurgery

VS Vestibular schwannoma

WHO World Health Organization

\section{Background}

Vestibular schwannomas (VS) are benign slow-growing tumors originating from Schwann cells insulating the eighth cranial nerve $[7,17]$. VS causes symptoms like tinnitus, hearing loss, and balance disturbances [21]. However, some VS are found incidentally and never cause symptoms 
[37]. The main treatments are surgery, stereotactic radiosurgery (SRS), or radiotherapy (RT). Complete surgical tumor removal has a high chance of being curative [35] but may cause hearing loss or facial nerve palsy $[3,34,36]$. SRS also has a high chance of being curative and a smaller risk of facial nerve palsy but is generally recommended

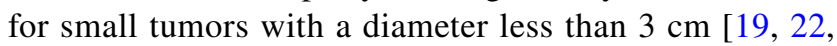
$29,45,48,49]$. Continued observation is recommended in asymptomatic patients without radiological growth $[14,38$, 39]. When making treatment decisions for VS patients, it is imperative to have up-to-date knowledge on probable outcomes for the different treatment options. As patients rarely die from a lack of tumor control, mortality and progressionfree survival are not sufficiently sensitive to identify the optimal treatment. Therefore, other "softer" outcome measures, such as depression and ability to work, are also of importance. Surveys have been used to study the quality of life after VS surgery, but as these are subjective and associated with many forms of bias, including an often quite problematic response bias $[6,10,16]$, it is desirable to complement these with objective methods for measuring patient-centered variables.

Antidepressant use is an objective measure highly correlated to depressive symptoms $[9,13]$, while the level of postoperative sick leave indicates the extent of disability in surgically treated patients. Only rudimentary data exist on how VS surgery impacts these important aspects. In this study, we describe the use of antidepressants and sedatives, as well as the patterns of sick leave rate, before and after surgical treatment of VS patients compared to a control population.

\section{Materials and methods}

The methods used in this manuscript have been described previously [42]. In short, we have combined data for each patient from several nationwide Swedish registries, linked through the unique personal identification numbers given to all citizens. We have used this approach to compare the rate of antidepressant use, sedative use, and sick leave between patients with VS and matched controls. Details regarding patient selection, the included registries, and the statistical analyses are presented below. Definitions of variables are available in Table 1.

\section{Patient selection}

We identified 346 patients in the Swedish Brain Tumor Registry (SBTR) surgically treated for a histopathological verified (according to the 2007 WHO classification) VS between April 1, 2009, and December 31, 2015. No duplicate cases were found, and all patients were $\geq 18$ years old. One patient who did not have a registered age was excluded. For each of the six regions providing information to the registry, we required an annual registration rate of $\geq 80 \%$ compared to the compulsory national cancer registry for the data to be included, resulting in the exclusion of 12 patients. The total cohort consisted of 333 patients. To study the impact of VS surgery on sick leave patterns, a subpopulation of patients within working age was defined. For this purpose, 90 patients with age $\geq 61$ years (of the main cohort with 333 patients) were excluded from the subpopulation since age $>60$ was considered to interfere with the decision to retire [42]. Of the remaining 242 patients, we excluded another 36 patients from the subpopulation that were not on registered sick leave on the day of surgery. As described previously [32, 42], this indicated that those patients were detached from the Swedish sick leave system and did not consistently receive compensation for sick leave. The remaining 206 patients constituted the return to work cohort (RTW cohort). See Table 1 for definitions. Every patient was matched to five unique controls, using matching criteria described below, yielding a control population of 1662 controls, of which 1025 were controls for the RTW cohort. One control registered as deceased, but without a registered date of death, it was excluded. For five patients, an incorrect number of controls was identified. See Supplementary Fig. 1 for a flowchart of patient selection.

\section{Linking of registries}

The linkage of SBTR to other national registries has been described in our previous studies [32, 42]. In short, SBTR is a nationwide, but regionally based, registry of adult ( $\geq 18$ years) patients with primary brain tumors, with a surgically acquired histopathological diagnosis. SBTR data was linked to several national registries: the patient registry and the prescription registry (part of National Board of Health and Welfare), the Register of the Total Population (part of Statistics Sweden), and the Swedish Social Insurance Agendy: MiDAS database. Statistics Sweden assigned the matched control population, where year of birth, sex, municipality of residence, and educational level were accounted for. All controls were unique. ICD-10 codes from the patient registry were used to calculate comorbidity according to the Elixhauser comorbidity index $[8,26]$. From the prescription registry, we received information concerning the type of drug according to the Anatomical Therapeutic Chemical (ATC) classification system and date of dispensing, for the period 2007-2017. Drug groups were defined using the ATC system. The group of antidepressants consisted of all drugs of the N06A (antidepressant) class. The sedative group consisted of all drugs of the N05B (anxiolytics) and N05C (hypnotics and sedatives) classes. 
Table 1 Definition of variables

\begin{tabular}{|c|c|c|}
\hline Variable & Definition & Source of information \\
\hline Index date & $\begin{array}{l}\text { Date of surgery for patients. Controls received the same index date as their } \\
\text { respective cases }\end{array}$ & SBTR \\
\hline Educational level & $\begin{array}{l}\text { Higher education was defined as having any registered completed secondary } \\
\text { or tertiary education (college or university) }\end{array}$ & Statistics Sweden \\
\hline Disposable income & $\begin{array}{l}\text { The sum of total personal yearly income (including salary, child-, and hous- } \\
\text { ing allowance) minus tax, in Swedish Crowns (SEK) }\end{array}$ & Statistics Sweden \\
\hline Return to work & $\begin{array}{l}\text { Assumed to have occurred if no longer receiving compensation. Return could } \\
\text { be partial }(25,50 \text {, or } 75 \%) \text { or complete }(100 \%)\end{array}$ & Swedish Social Insurance Agency \\
\hline Net days absent & $\begin{array}{l}\text { A construct of days and grade of compensation where days multiplied with a } \\
\text { degree of compensation created a value between } 0 \text { and } 365 \text { in a year }\end{array}$ & Swedish Social Insurance Agency \\
\hline History of depression & $\begin{array}{l}\text { ATC: N06A and/or "depression" according to Elixhauser comorbidity index } \\
(\mathrm{F} 20.4, \mathrm{~F} 31.3-\mathrm{F} 31.5, \mathrm{~F} 32, \mathrm{~F} 33, \mathrm{~F} 34.1, \mathrm{~F} 41.2, \mathrm{~F} 43.2)\end{array}$ & NPR and NPrR \\
\hline History of seizure & $\begin{array}{l}\text { Any previous prescription of ATC: N03A and/or ICD-10: G40. Also, if regis- } \\
\text { tered "seizure" as a symptom in SBTR }\end{array}$ & NPR, NPrR, and SBTR \\
\hline Elixhauser comorbidity index & $\begin{array}{l}\text { According to the index, depression was removed as it is reported separately. } \\
\text { The following conditions were removed from the index due to possible } \\
\text { association with diagnosis of VS: } \\
\text { C70-72: Malignant tumor in the central nervous system } \\
\text { Using this index, both cases and controls received a score of comorbid cat- } \\
\text { egories. We report as } 0,1,2 \text {, or } \geq 3 \text { categories present }\end{array}$ & NPR \\
\hline Prescription group & $\begin{array}{l}\text { All drugs with a common ATC code. Groups were defined as follows: } \\
\text { Antidepressants: ATC class N06A (antidepressants) } \\
\text { Sedatives: ATC class N05B (anxiolytics, including benzodiazepines) and } \\
\text { N05C (hypnotics and sedatives) }\end{array}$ & NPrR \\
\hline Active use & $\begin{array}{l}\text { Active use of a prescription group was defined as having received any pre- } \\
\text { scription of a drug of this prescription group in the prior } 90 \text { days } \\
\text { For the prescription group "sedatives," the patient was considered an active } \\
\text { user only for } 30 \text { days after a drug prescription } \\
\text { When calculating the percentage of the population that is active users, only } \\
\text { alive individuals were considered }\end{array}$ & NPrR \\
\hline
\end{tabular}

$A T C$, anatomical therapeutic chemical; $S B T R$, Swedish brain tumor registry; $N P R$, national patient registry; $N P r R$, national prescription registry

Fig. 1 Graph representing the proportions $(95 \% \mathrm{CI})$ of patients (red) and controls (blue) with active use of antidepressants 2 years prior to the index date through 2 years following the index date

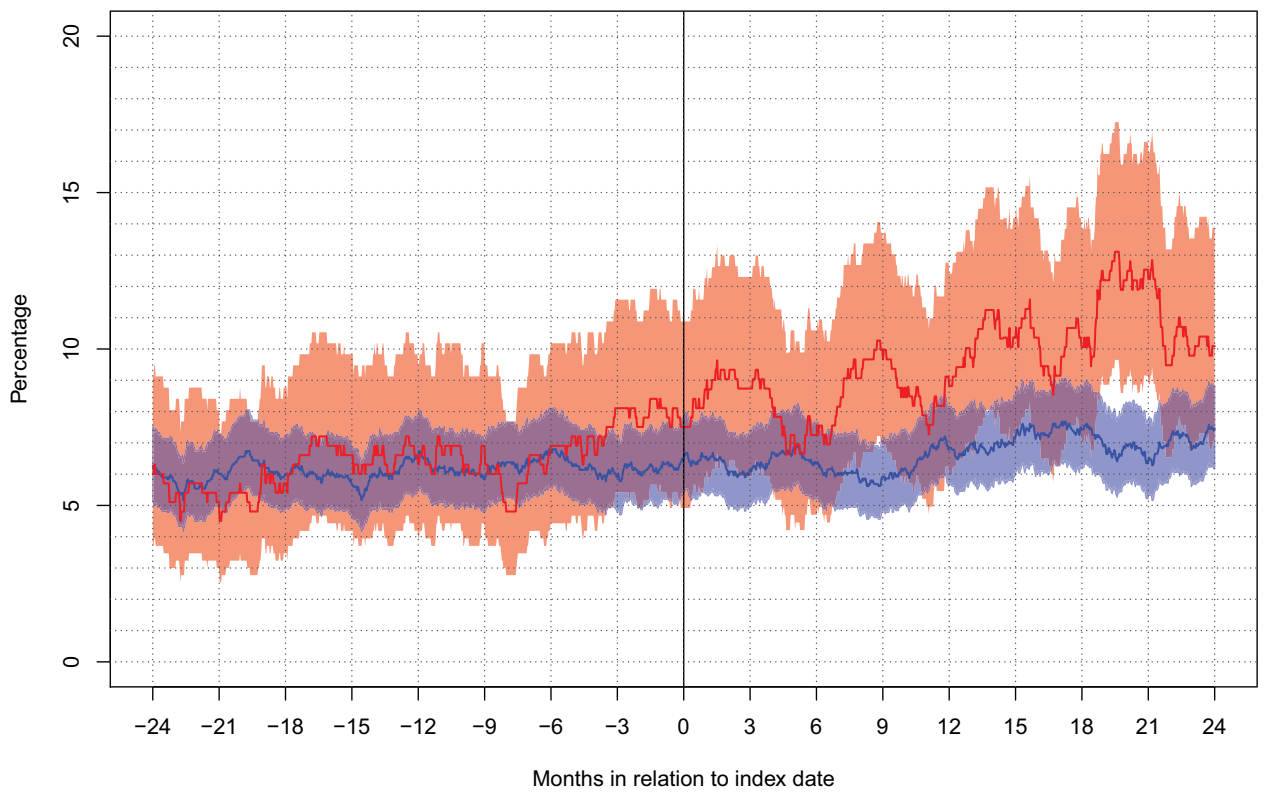




\section{Statistics}

In short, data from the registries were imported into corresponding tables in a mySQL database. Data on drug prescriptions (date and ATC code) and sick leave (dates and degree) were individually analyzed for each patient and combined with clinical data using Python. Definitions regarding the prescription groups and regarding active use are provided in Table 1. Other data derivations were done using mySQL. $R$ was used for statistical analyses. The index date and date of diagnosis were defined as the date of surgery. For each day from 2 years ( 730 days) before until 2 years after the index date, we calculated the proportion of patients and controls that were active users of the different prescription groups and the proportion of patients and controls that were on full sick leave, partial sick leave, or without any sick leave. The proportions were displayed as graphs. Analyzing Elixhauser comorbidity, we excluded conditions associated with VS, as defined in Table $1[8,26]$.

Other data derivations were done using mySQL. R version 2.13.1 was used for statistical analyses. Continuous variables were summarized using the median, first, and third quartiles, and compared between cases and controls using the Mann-Whitney $U$ test. Categorical variables were summarized using counts and proportions and compared between cases and controls using Fisher's exact test.

Univariable and multivariable logistic regressions were used to examine predictors for RTW (partial or complete) at the end of the follow-up at 2 years postoperatively. Variables were selected based on presumed relevance.

\section{Ethics statement}

This study was approved by the regional ethical committee in the Västra Götaland region (Dnr: 363-17).

\section{Results}

\section{Demographic data}

Baseline characteristics of the 333 included patients are presented in Table 2. The median age was 52 years and $48 \%$ of the population was females. The majority of patients $(85 \%)$ could perform at least light work (i.e., WHO functional status $0-1$ ) at the time of surgery. The preoperative neurologic deficit, including auditory symptoms, was present in $87 \%$ of patients, while $7 \%$ were asymptomatic preoperatively. Most patients $(86 \%)$ had tumors measuring $<4 \mathrm{~cm}$, only four patients $(2 \%)$ had tumors measuring $>6 \mathrm{~cm}$. Gross total resection was achieved in 68\%, near-total resection in $7 \%$, and partial resection in $26 \%$ of patients.

\section{Patterns of antidepressant and sedative use}

A comparison between all VS patients $(n=333)$ and all controls $(n=1662)$ regarding socioeconomic variables, comorbidity, and patterns of antidepressant and sedative use is summarized in Table 3. The percentage of patients and controls with active use of each of the defined drug groups is presented at 2 years before until 2 years following index date in Figs. 1 and 2. There were no significant differences between patients and controls regarding the use of antidepressants and sedatives at the index date, at 2 years prior to surgery, or at 2 years following surgery. As seen in Fig. 2, the use of sedatives among patients was significantly higher than for controls around 1-2 months after surgery but then dropped to the level of the controls.

\section{Return to work}

The RTW cohort $(n=206)$ and respective controls $(n=1025)$ are summarized regarding patterns of sick leave in Table 4. Absence from work in the 2 years preceding surgery up to 2 years following surgery for the RTW cohort is presented in separate graphs for patients (Fig. 3) and controls (Fig. 4).

At 1 year before surgery, $88 \%$ of patients did not have any registered sick leave. The rate of complete RTW (no sick leave) among patients was $25 \%$ at 3 months, $53 \%$ at 6 months, $67 \%$ at 1 year, and $75 \%$ at 2 years after surgery. The rate of controls without any registered sick leave was stable at $88-92 \%$ during the studied time.

\section{Predictors for returning to work}

To establish predictors for RTW at 2 years after VS surgery, a logistic regression model was created (Supplementary Table 1). We found that net days absent in the year preceding surgery (OR $0.91,95 \%$ CI $0.89-0.93, p<0.001$ ), use of sedatives at the index date (OR $0.60,95 \%$ CI $0.38-0.94$, $p=0.03$ ), and surgically acquired neurological deficits (OR $0.42,95 \%$ CI $0.24-0.76, p=0.004$ ) were all negatively associated with RTW at 2 years after surgery.

\section{Discussion}

In this nationwide register-based study, we demonstrated that the rates of antidepressant and sedative use were not significantly different for patients 2 years after VS surgery compared to matched controls, but only $75 \%$ of patients were in full-time employment, compared to $88 \%$ of matched controls 2 years after surgery. Predictors for being on sick leave 2 years after surgery were sedative use at the index date, more preoperative sick leave, and new-onset neurological deficits after surgery. 
Table 2 Baseline and treatment characteristics for patients with vestibular schwannoma

\begin{tabular}{|c|c|c|}
\hline Variable & RTW cohort $(n=206)$ & All patients $(n=333)$ \\
\hline Age, median (Q1, Q3) & $46(36,53)$ & $52(40,61)$ \\
\hline Female, $n(\%)$ & $91(44.2)$ & $161(48.3)$ \\
\hline \multicolumn{3}{|l|}{ WHO functional status, $n(\%)$} \\
\hline 0 , fully active & $144(71.0)$ & $210(64.4)$ \\
\hline 1, light work possible & $39(19.2)$ & $68(20.9)$ \\
\hline 2 , cares for self & $18(8.9)$ & $41(12.6)$ \\
\hline 3 , limited self-care & $1(0.5)$ & $6(1.8)$ \\
\hline 4, disabled, confined to bed & $1(0.5)$ & $1(0.3)$ \\
\hline Missing & 3 & 7 \\
\hline Asymptomatic preoperatively, $n(\%)$ & $12(5.8)$ & $23(6.9)$ \\
\hline Neurologic deficit preoperatively, $n(\%)$ & $178(86.4)$ & $288(86.5)$ \\
\hline \multicolumn{3}{|l|}{ Tumor laterality, $n(\%)$} \\
\hline Left & $100(51.3)$ & $162(47.9)$ \\
\hline Right & $94(48.2)$ & $151(51.4)$ \\
\hline Bilateral & $1(0.5)$ & $2(0.6)$ \\
\hline Missing & 11 & 18 \\
\hline \multicolumn{3}{|l|}{ Tumor size, $n(\%)$} \\
\hline$<4 \mathrm{~cm}$ & $149(85.6)$ & $244(85.9)$ \\
\hline $4-6 \mathrm{~cm}$ & $21(12.1)$ & $36(12.7)$ \\
\hline$>6 \mathrm{~cm}$ & $4(2.3)$ & $4(1.4)$ \\
\hline Missing & 32 & 49 \\
\hline \multicolumn{3}{|l|}{ Extent of resection, $n(\%)$} \\
\hline Partial resection & $53(25.7)$ & $93(27.9)$ \\
\hline Near total resection & $14(6.8)$ & $18(5.4)$ \\
\hline Total resection & $139(67.5)$ & $222(66.7)$ \\
\hline New deficit after surgery, $n(\%)$ & $58(28.2)$ & $93(27.9)$ \\
\hline \multicolumn{3}{|l|}{ Postoperative complications } \\
\hline Infection, $n(\%)$ & $25(12.1)$ & $34(10.2)$ \\
\hline Hemorrhage, $n(\%)$ & $7(3.4)$ & $10(3.0)$ \\
\hline Venous thromboembolism, $n(\%)$ & $1(3.9)$ & $10(3.0)$ \\
\hline Seizure, $n(\%)$ & 0 & 0 \\
\hline Reoperation due to complication, $n(\%)$ & $15(7.3)$ & $21(6.3)$ \\
\hline Oncological treatment planned, $n(\%)$ & $8(3.9)$ & $9(2.7)$ \\
\hline Missing & 1 & 1 \\
\hline
\end{tabular}

\section{Drug use}

The main indication for antidepressants is major depressive disorder (MDD). Antidepressants are also prescribed for other conditions with partially overlapping diagnostic criteria, such as anxiety disorders and sleep disorders, and use is increasing [24]. The rate of antidepressant use is tightly correlated to the severity of depressive symptoms [9] and has been utilized to indicate the prevalence of depression [13].

In the present study, the use of antidepressants was similar between cases and controls at 2 years before surgery, at the index date, and at 2 years after surgery. This is in line with a previous cross-sectional study of 205 VS patients using validated questionnaires to measure symptoms of depression and anxiety at different time points after diagnosis or treatment for VS, concluding that anxiety and depression scores did not differ from the general population [4]. The same study also reported that surgical management, radiation, and observational management were associated with anxiety and depression scores similar to those of controls [4].

The low levels of antidepressant use in VS patients are interesting considering what is known for low-grade glioma [33] and meningioma [43], where the rate of antidepressant use is distinctly increased after surgery. For low-grade glioma, the increased use of antidepressants is presumably related to the higher morbidity and mortality. For meningiomas, the reason is more elusive but could be related to that the outcome after VS surgery is generally more predictable, as meningiomas have a higher degree of variance concerning 
Table 3 Characteristics of patients and controls concerning socioeconomic factors and use of mood-related medications

\begin{tabular}{|c|c|c|c|}
\hline & All patients $(n=333)$ & All controls $(n=1662)$ & $p$-value \\
\hline \multicolumn{4}{|l|}{ Educational level, at the index year, $n(\%)$} \\
\hline Basic to high school & $208(63.4)$ & $1030(62.9)$ & \multirow[t]{3}{*}{0.86} \\
\hline Higher education & $120(36.6)$ & $607(37.1)$ & \\
\hline Missing & 5 & 253 & \\
\hline \multicolumn{4}{|l|}{ Disposable income, 1000 SEK } \\
\hline Median (Q1, Q3) & $218(158,286)$ & $231(154,310)$ & 0.19 \\
\hline \multicolumn{4}{|l|}{ Elixhauser comorbidities, at the index date, $n(\%)$} \\
\hline 0 & $276(82.9)$ & $1446(87.0)$ & \multirow{4}{*}{0.23} \\
\hline 1 & $39(11.7)$ & $144(8.7)$ & \\
\hline 2 & $12(3.6)$ & $44(2.6)$ & \\
\hline 3 or more & $6(1.8)$ & $28(1.7)$ & \\
\hline Use of antidepressants at 2 years before the index date, $n(\%)$ & $20(6.0)$ & $104(6.3)$ & 1.0 \\
\hline Use of sedatives at 2 years before the index date, $n(\%)$ & $13(3.9)$ & $72(4.3)$ & 0.88 \\
\hline Use of antidepressants at the index date, $n(\%)$ & $25(7.5)$ & $107(6.4)$ & 0.64 \\
\hline Use of sedatives at the index date, $n(\%)$ & $23(6.9)$ & $64(3.8)$ & 0.08 \\
\hline Use of antidepressants at 2 years after the index date, $n / n$ alive ( $\%$ of alive) & $33 / 327(10.1)$ & $122 / 1637(7.5)$ & 0.15 \\
\hline Use of sedatives at 2 years after the index date, $n / n$ alive ( $\%$ of alive) & $16 / 327(4.8)$ & $87 / 1637(5.3)$ & 0.85 \\
\hline
\end{tabular}

tumor location and symptoms and can cause seizures or cognitive symptoms. Meningioma surgery is also associated with a higher risk for complications than VS surgery [1, 5].

Sedatives are mainly prescribed for symptoms of anxiety and sleep disorders. They provide short-term symptom relief but have the potential for addiction, both through psychological and pharmacological mechanisms [46]. In addition, long-term use can have detrimental effects on health [41]. The baseline level of $4.3 \%$ for controls 2 years before the index date was in line with previous reports of sedative use in the general population $[2,30]$.
The rate of sedative use for VS patients at the index date was $6.9 \%$ for patients and $3.8 \%$ for controls. Thus, there was a trend towards increased sedative use for VS patients at the index date in our material, but no significant difference was found neither at 2 years before surgery, at the index date, or at 2 years after surgery.

Our study of a comparable population undergoing meningioma surgery during a similar time period demonstrated a clear peak around the time of surgery and a slight increase in long-term sedative use [43]. The expected brief, but significant, increase in sedative use for patients a few weeks
Fig. 2 Graph representing the proportions $(95 \% \mathrm{CI})$ of patients (red) and controls (blue) with active use of sedatives 2 years prior to the index date through 2 years following the index date

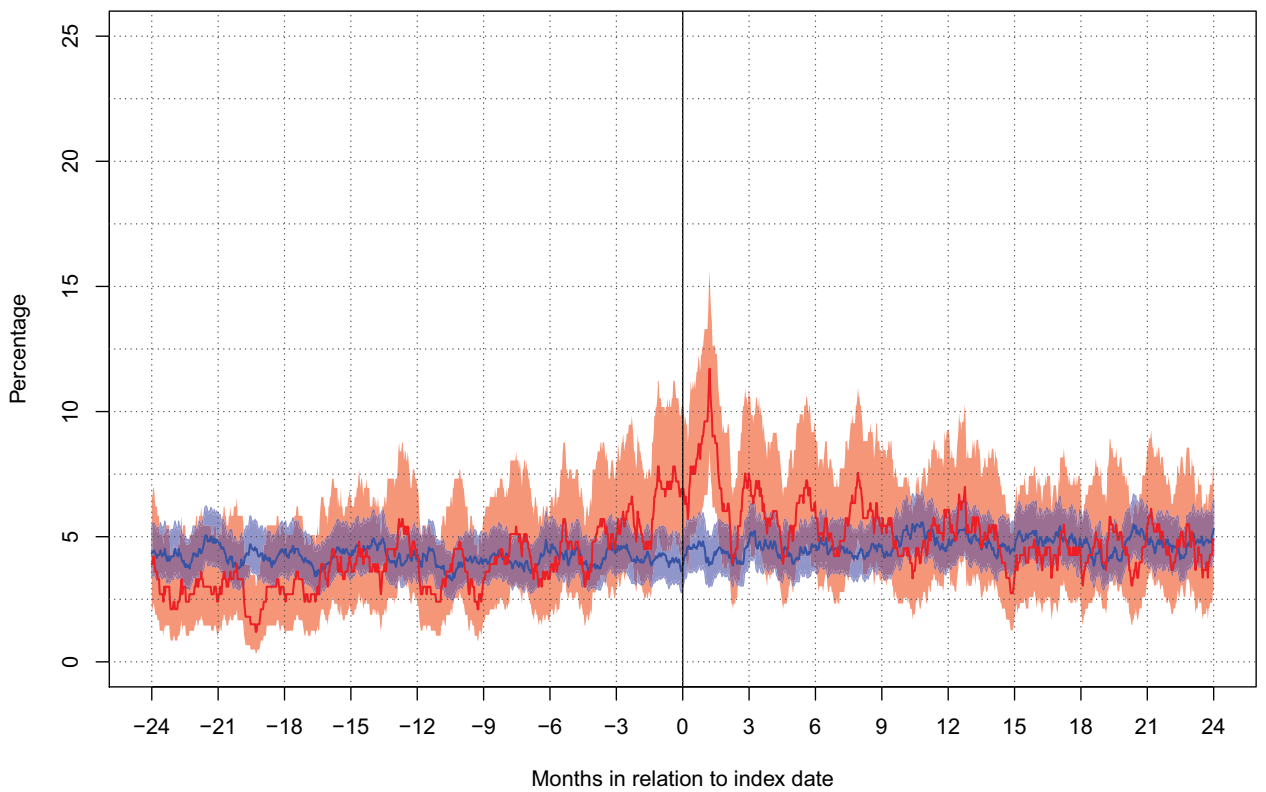


Table 4 Subgroup analysis: quantification of postoperative disability among vestibular schwannoma patients in the workforce, compared to their controls

\begin{tabular}{|c|c|c|c|}
\hline & RTW cohort $(n=206)$ & Controls $(n=1025)$ & $p$-value \\
\hline Net days absent 365 days prior to the index date, median (Q1, Q3) & $5(1,53)$ & $0(0,0)$ & $<0.01$ \\
\hline$\%$ on permanent sick leave at the index date & $13(6.3)$ & $42(4.1)$ & 0.64 \\
\hline Net days absent 1 year after the index date, median (Q1, Q3) & $136(89,329)$ & $0(0,0)$ & $<0.01$ \\
\hline Net days absent between 1 and 2 years after the index date, median (Q1, Q3) & $0(0,140)$ & $0(0,0)$ & $<0.01$ \\
\hline Without any sick leave compensation at 2 years before the index date, $n(\%)$ & $188(91.2)$ & $924(90.1)$ & 0.62 \\
\hline Without any sick leave compensation at 1 year before the index date, $n(\%)$ & $181(87.9)$ & $926(90.3)$ & 0.46 \\
\hline Without any sick leave compensation at 1 year after the index date, $n(\%)$ & $137(66.5)$ & $927(90.4)$ & $<0.01$ \\
\hline Without any sick leave compensation 2 years after the index date, $n(\%)$ & $155(75.2)$ & $907(88.5)$ & $<0.01$ \\
\hline On permanent sick leave 365 days after the index date, $n(\%)$ & $13(6.3)$ & $40(3.9)$ & 0.35 \\
\hline
\end{tabular}

after the index date did not cause long-term increased use in patients with VS.

\section{Return to work}

The baseline level of sick leave for VS patients did not differ from the level for controls at 1 year before surgery (12\% vs $10 \%)$. After surgery, more than half of VS patients had returned to work after 6 months, $66 \%$ after 1 year, and $75 \%$ after 2 years, while sick leave for controls remained stable. This contrasts with a 2009 study comparing surgery to SRS for VS patients. Among 22 non-retired surgically treated patients, 64\% (14/22) were working 2 years after surgery. The SRS group had a lower RTW rate of $61 \%$ (27/44) but was older and had more retirements. Besides a small sample size, the study included patients above the age of 60 , and it is not entirely clear how sick leave was defined and measured, potentially explaining the disparity in our data [20].

A 2002 questionnaire study of unilateral non-neurofibromatosis VS comparing VS surgery to SRS reported that in the surgically treated group of 110 included patients, $67 \%$ had returned to work at the time of follow-up. Comparisons to our material are somewhat difficult as the time from treatment to follow-up for surgical patients was not clearly stated and RTW was self-reported. Also, patients older than 60 were not excluded (the mean age was 61 years), presumably contributing to a relatively low RTW rate [27].

As with drug use, the rate of sick leave after VS surgery in our material is strikingly low compared to meningioma patients during the same time in the same region [42]. Compared to meningioma patients, VS patients appear less affected by their disease before surgery and the risk for
Fig. 3 Stacked graph demonstrating, in patients with vestibular schwannoma $(n=206)$, the rates without sick leave compensation (green), with partial compensation (yellow), and with full compensation (red) from 365 days prior to the index date to 730 days after the index date. The dark gray stack at the bottom represents deceased patients

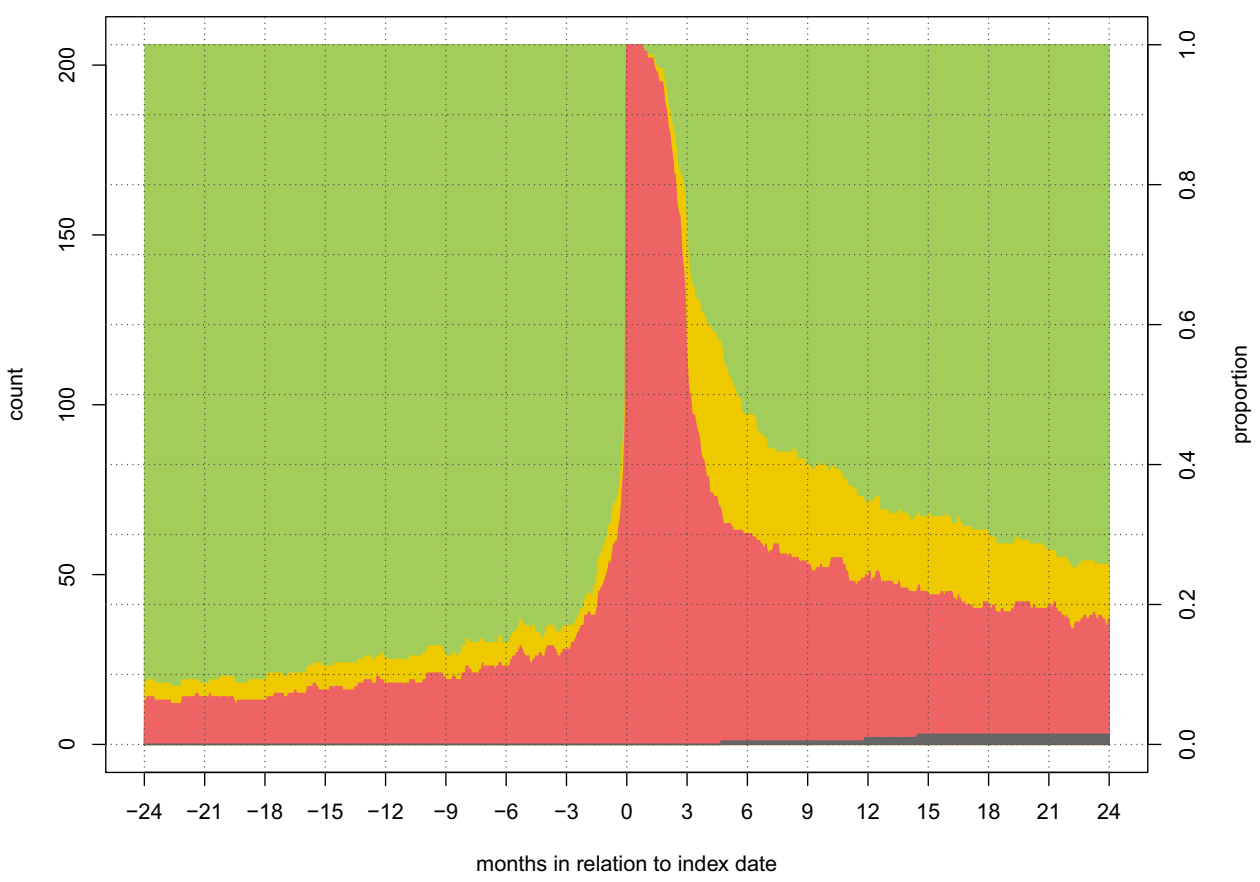


Fig. 4 Stacked graph demonstrating, in matched controls $(n=1025)$, the rates without sick leave compensation (green), with partial compensation (yellow), and with full compensation (red) from 365 days prior to the index date to 730 days after the index date. The dark gray stack at the bottom represents deceased patients

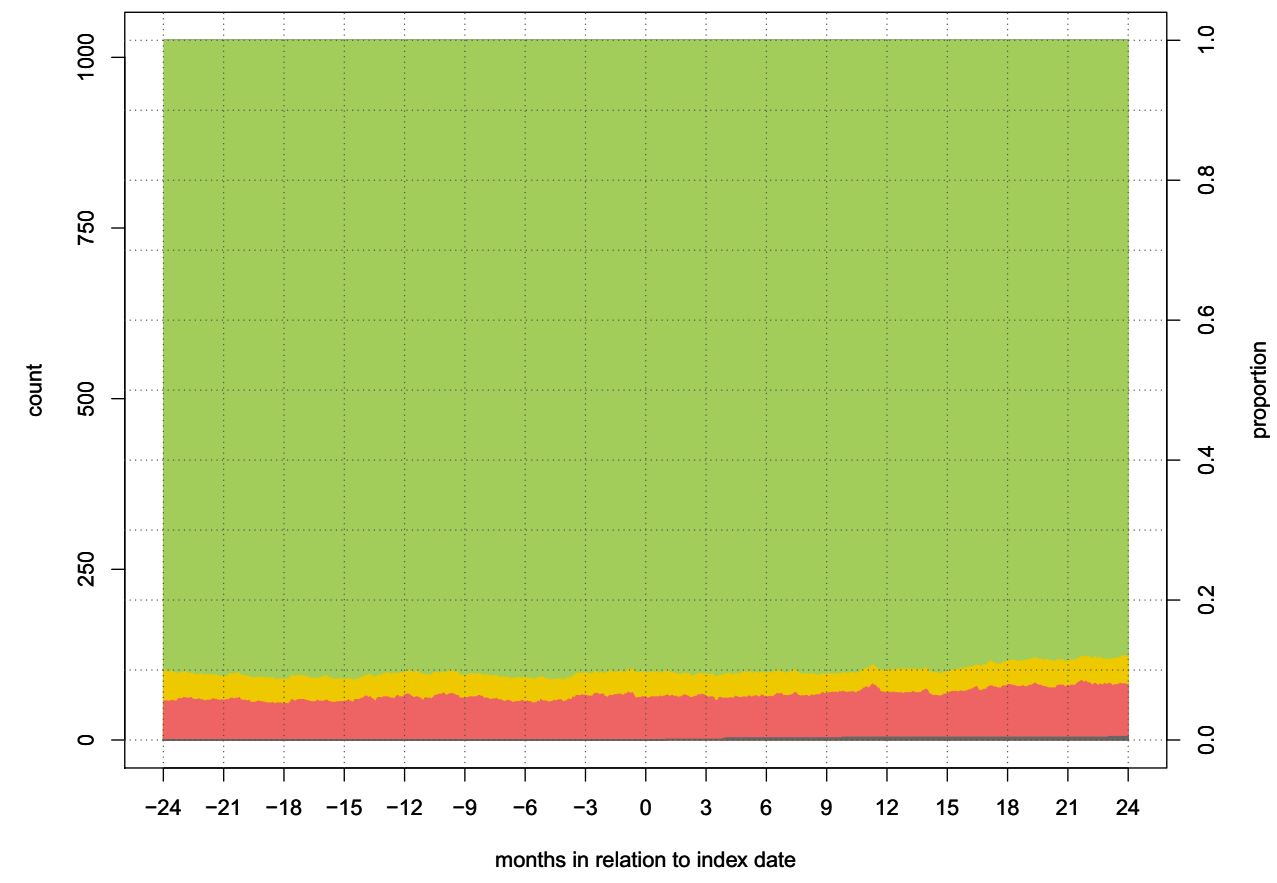

complications affecting the ability to work in this patient group is lower $[1,5]$.

A large VS may compress the cerebellum and brainstem rather than the cerebrum and therefore be less inclined to cause cognitive symptoms. It has been shown for stroke patients that cortical neurological symptoms (such as language), but not location per se, are negatively correlated with RTW [47]. This observation could be relevant also when considering the risk of sick leave among VS patients compared to supratentorial disorders.

We observed that the rate of sick leave depends heavily on the timing of assessment and can be radically different at 1, 3, or 6 months after surgery. Therefore, comparisons between studies are difficult if the studied time points are not clearly defined. Many studies of sick leave and disability concerning VS surgery do not take this into consideration. This is a limitation in cross-sectional studies where patients are assessed at various time points. We recommend that prior to planning future studies, care should be taken to define the time point in relation to surgery for each measurement to be made, and researchers may find the figures presented in this manuscript useful in their planning.

In the multivariable regression model, we found that having more sick leaves in the year preceding surgery predicted not having returned to work 2 years after surgery. This is reasonable, considering that a history of sick leave has been shown to decrease the probability of RTW [15, 18] and that previous sick leave predicts future episodes of sick leave [12, 31].

An interesting finding was that sedative use at the index date was negatively associated with RTW at 2 years after surgery. Sick leave for psychological causes (such as depression or anxiety) is not uncommon and is associated with an increased risk of persisting into long-term sick leave [23]. Benzodiazepine use has been shown to correlate with unemployment [28]. The use of benzodiazepine also increases the likelihood for episodes of sick leave, although it is not clear by what mechanism [11]. Although sick leave has been associated with depression [28], the use of antidepressants did not predict sick leave in our study. Based on our findings, one may speculate if minimizing the use of sedatives around the time of surgery can increase the rate of RTW. However, further studies are needed to clarify the cause-effect relationship of this finding. Finally, we found that new-onset neurologic deficit after surgery reduced the probability of RTW at 2 years postoperatively. Because this variable is potentially modifiable, this finding is a reminder of the importance to minimize the risks of VS surgery.

\section{Strengths and limitations}

The present study is an observational study. Inherently, this limits our ability to draw causal conclusions about the relationship between surgical treatment of VS and the studied outcome measures. We are also limited by the variables collected by the registries, where interesting variables such as surgical approach were not included. VS treated with upfront radiotherapy without histopathological verification would be interesting but were also not included in the data of the present study. Other variables, although present, were crude. For instance, the variable "new neurological deficit" may include both predictable loss of hearing, facial nerve injury, 
and/or unexpected neurological deterioration. Another limitation is that we had no access to which other interventions, for instance, psychotherapy, were used to treat depression.

A strength of the study is the nationwide registry, significantly reducing many forms of selection bias. The 333 patients included constitute a relatively large population considering that VS is rare, with a yearly incidence of around 1-2 per 100,000 inhabitants per year and that only a subset of VS patients requires surgery [40,44]. Another strength of our study is that the avoidance of response bias, as the reporting to the national registries, has been mandatory. This is important because outlier groups can have aberrant response patterns, and nonresponse bias can severely skew results if the response rate is below $80 \%$.

We have not compared VS surgery to other treatment forms, such as observation or SRS. Since we studied only surgically treated patients, it is likely that large and symptomatic VS are more common in our material than in a wider cohort of VS patients. VS with a radiological, but no histological diagnosis, however, constitutes a continuum of entities from miniscule uncertain findings to large tumors, making these hard to define and study.

From an international perspective, Sweden has a generous policy regarding the degree and length of sick leave. This may affect the external validity of the results in this article. To compensate for this, we have included matched controls in the study.

\section{Conclusions}

The use of antidepressants and sedatives, and the rate of sick leave, was similar between VS patients and controls at baseline preoperatively. No differences were found between patients and controls regarding antidepressant and sedative use at the time of surgery or at 2 years after surgery. However, at 2 years after surgery, considerably more patients than controls were on sick leave. The risk for long-term sick leave increased in patients with more sick leave during the year preceding surgery, in patients using sedatives, and if surgery resulted in new neurological deficit(s).

Supplementary Information The online version contains supplementary material available at https://doi.org/10.1007/s00701-021-04862-8.

Acknowledgements This project was made possible by the continuous work of the Swedish Brain Tumor Registry (SBTR).

Funding Open access funding provided by University of Gothenburg. This project was funded by a research grant from the Swedish Research Council (2017-00944).

\section{Declarations}

Conflict of interest The authors declare no competing interests.
Open Access This article is licensed under a Creative Commons Attribution 4.0 International License, which permits use, sharing, adaptation, distribution and reproduction in any medium or format, as long as you give appropriate credit to the original author(s) and the source, provide a link to the Creative Commons licence, and indicate if changes were made. The images or other third party material in this article are included in the article's Creative Commons licence, unless indicated otherwise in a credit line to the material. If material is not included in the article's Creative Commons licence and your intended use is not permitted by statutory regulation or exceeds the permitted use, you will need to obtain permission directly from the copyright holder. To view a copy of this licence, visit http://creativecommons.org/licenses/by/4.0/.

\section{References}

1. Bartek J Jr, Forander P, Thurin E, Henriksson R, Hesselager G, Jakola AS, Wangerid T (2019) Short-term surgical outcome for vestibular schwannoma in Sweden: a nation-wide registry study. Front Neurol 10:43

2. Bertisch SM, Herzig SJ, Winkelman JW, Buettner C (2014) National use of prescription medications for insomnia: NHANES 1999-2010. Sleep 37:343-349. https://doi.org/10. 5665/sleep. 3410

3. Brackmann DE, Owens RM, Friedman RA, Hitselberger WE, De la Cruz A, House JW, Nelson RA, Luxford WM, Slattery WH 3rd, Fayad JN (2000) Prognostic factors for hearing preservation in vestibular schwannoma surgery. Am J Otol 21:417-424

4. Brooker JE, Fletcher JM, Dally MJ, Briggs RJS, Cousins VC, Malham GM, Smee RI, Kennedy RJ, Burney S (2012) Factors associated with anxiety and depression in the management of acoustic neuroma patients. J Clin Neurosci 19:246-251. https:// doi.org/10.1016/j.jocn.2011.06.006

5. Corell A, Thurin E, Skoglund T, Farahmand D, Henriksson R, Rydenhag B, Gulati S, Bartek J Jr, Jakola AS (2019) Neurosurgical treatment and outcome patterns of meningioma in Sweden: a nationwide registry-based study. Acta Neurochir 161:333-341. https://doi.org/10.1007/s00701-019-03799-3

6. de Souto BP (2012) Participation bias in postal surveys among older adults: The role played by self-reported health, physical functional decline and frailty. Arch GerontolGeriatr 55:592-598

7. Eldridge R, Parry D (1992) Vestibular schwannoma (acoustic neuroma). Consensus development conference Neurosurgery 30:962-964

8. Elixhauser A, Steiner C, Harris DR, Coffey R (1998) Comorbidity measures for use with administrative data. Med care 36(1):8-27

9. Ellervik C, Kvetny J, Christensen KS, Vestergaard M, Bech P (2014) Prevalence of depression, quality of life and antidepressant treatment in the Danish General Suburban Population Study. Nord J Psychiatry 68:507-512. https://doi.org/10.3109/ 08039488.2013.877074

10. Etter J-F, Perneger TV (1997) Analysis of non-response bias in a mailed health survey. J Clin Epidemiol 50:1123-1128

11. Hori H, Katsuki A, Atake K, Yoshimura R, Nakamura J, Baune BT (2019) Risk factors for further sick leave among Japanese workers returning to work after an episode of major depressive disorder: a prospective follow-up study over 1 year. BMJ Open 9:e029705. https://doi.org/10.1136/bmjopen-2019-029705

12. Hultin H, Lindholm C, Malfert M, Möller J (2012) Short-term sick leave and future risk of sickness absence and unemployment - the impact of health status. BMC Public Health 12:861. https://doi.org/10.1186/1471-2458-12-861

13. Johannsdottir IM, Karlstad Ø, Loge JH, Fosså SD, Kiserud C, Skurtveit S (2017) Prescriptions of antidepressants to survivors of cancer in childhood, adolescence, and young adulthood: a 
population-based study. J Adolesc Young Adult Oncol 6:12126. https://doi.org/10.1089/jayao.2016.0041

14. Kondziolka D, Mousavi SH, Kano H, Flickinger JC, Lunsford LD (2012) The newly diagnosed vestibular schwannoma: radiosurgery, resection, or observation? Neurosurg Focus 33:E8. https://doi.org/10.3171/2012.6.FOCUS12192

15. Koopmans P, Roelen C, Groothoff J (2008) Risk of future sickness absence in frequent and long-term absentees. Occupational medicine (Oxford, England) 58:268-274. https://doi.org/10. 1093/occmed/kqn040

16. Kotaniemi J-T, Hassi J, Kataja M, Jönsson E, Laitinen LA, Sovijärvi AR, Lundbäck B (2001) Does non-responder bias have a significant effect on the results in a postal questionnaire study? Eur J Epidemiol 17:809-817

17. Luetje CM, Whittaker CK, Callaway LA, Veraga G (1983) Histological acoustic tumor involvement of the VIIth nerve and multicentric origin in the VIIIth nerve. Laryngoscope 93:1133-1139

18. Lund T, Kivimäki M, Labriola M, Villadsen E, Christensen KB (2008) Using administrative sickness absence data as a marker of future disability pension: the prospective DREAM study of Danish private sector employees. Occup Environ Med 65:28-31. https://doi.org/10.1136/oem.2006.031393

19. Mahboubi H, Sahyouni R, Moshtaghi O, Tadokoro K, Ghavami Y, Ziai K, Lin HW, Djalilian HR (2017) CyberKnife for treatment of vestibular schwannoma: a meta-analysis. Otolaryngol Head Neck Surg 157:7-15. https://doi.org/10.1177/0194599817695805

20. Myrseth E, Møller P, Pedersen P-H, Lund-Johansen M (2009) Vestibular schwannoma: surgery or gamma knife radiosurgery? A prospective, nonrandomized study. Neurosurgery 64:654-663

21. Myrseth E, Pedersen PH, Moller P, Lund-Johansen M (2007) Treatment of vestibular schwannomas Why, when and how? ActaNeurochir (Wien) 149:647-660. https://doi.org/10.1007/s00701007-1179-0 (discussion 660)

22. Nuseir A, Sequino G, De Donato G, Taibah A, Sanna M (2012) Surgical management of vestibular schwannoma in elderly patients. Eur Arch Otorhinolaryngol 269:17-23. https://doi.org/ 10.1007/s00405-011-1566-2

23. Nystuen P, Hagen KB, Herrin J (2001) Mental health problems as a cause of long-term sick leave in the Norwegian workforce. Scand J Public Health 29:175-182. https://doi.org/10.1177/14034 948010290030301

24. Olfson M, Marcus SC (2009) National patterns in antidepressant medication treatment. Arch Gen Psychiatry 66:848-856. https:// doi.org/10.1001/archgenpsychiatry.2009.81

25. Pringle AM, Taylor R, Whittle IR (1999) Anxiety and depression in patients with an intracranial neoplasm before and after tumour surgery. Br J Neurosurg 13:46-51. https://doi.org/10.1080/02688 699944177

26. Quan H, Sundararajan V, Halfon P, Fong A, Burnand B, Luthi JC, Saunders LD, Beck CA, Feasby TE, Ghali WA (2005) Coding algorithms for defining comorbidities in ICD-9-CM and ICD-10 administrative data. Med Care 43:1130-1139

27. Régis J, Pellet W, Delsanti C, Dufour H, Roche PH, Thomassin JM, Zanaret M, Peragut JC (2002) Functional outcome after gamma knife surgery or microsurgery for vestibular schwannomas. J Neurosurg 97:1091-1100. https://doi.org/10.3171/jns.2002. 97.5.1091

28. Rizvi SJ, Cyriac A, Grima E, Tan M, Lin P, Gallaugher LA, McIntyre RS, Kennedy SH (2015) Depression and employment status in primary and tertiary care settings. Can J Psychiatr 60:14-22

29. Roehm PC, Gantz BJ (2007) Management of acoustic neuromas in patients 65 years or older. Otol Neurotol 28:708-714. https:// doi.org/10.1097/01.mao.0000281805.44197.ec

30. Roehrs T, Roth T (2004) 'Hypnotic'prescription patterns in a large managed-care population. Sleep Med 5:463-466
31. Roelen CA, Koopmans PC, Schreuder JA, Anema JR, van der Beek AJ (2011) The history of registered sickness absence predicts future sickness absence. Occup Med (Lond) 61:96-101. https://doi.org/10.1093/occmed/kqq181

32. Rydén I, Carstam L, Gulati S, Smits A, Sunnerhagen KS, Hellström P, Henriksson R, Bartek J Jr, Salvesen Ø, Jakola AS (2020) Return to work following diagnosis of low-grade glioma. A nationwide matched cohort study Neurology 95:e856-e866. https://doi.org/10.1212/wnl.0000000000009982

33. Rydén I, Thurin E, Carstam L, Smits A, Gulati S, Henriksson R, Salvesen Ø, Jakola AS (2021) Psychotropic and anti-epileptic drug use, before and after surgery, among patients with lowgrade glioma: a nationwide matched cohort study. BMC Cancer 21(1):248. https://doi.org/10.1186/s12885-021-07939-w

34. Samii M, Gerganov V, Samii A (2006) Improved preservation of hearing and facial nerve function in vestibular schwannoma surgery via the retrosigmoid approach in a series of 200 patients. J Neurosurg 105:527-535. https://doi.org/10.3171/jns.2006.105.4. 527

35. Samii M, Matthies C (1997) Management of 1000 vestibular schwannomas (acoustic neuromas): surgical management and results with an emphasis on complications and how to avoid them. Neurosurgery 40:11-21 (discussion 21-13)

36. Sanna M, Khrais T, Russo A, Piccirillo E, Augurio A (2004) Hearing preservation surgery in vestibular schwannoma: the hidden truth. Ann Otol Rhinol Laryngol 113:156-163. https://doi.org/ $10.1177 / 000348940411300215$

37. Solheim O, Torsteinsen M, Johannesen TB, Jakola AS (2014) Effects of cerebral magnetic resonance imaging in outpatients on observed incidence of intracranial tumors and patient survival: a national observational study. J Neurosurg 120:827. https://doi.org/ 10.3171/2013.12.Jns 131312

38. Stangerup SE, Caye-Thomasen P (2012) Epidemiology and natural history of vestibular schwannomas. Otolaryngol Clin North Am 45(257-268):vii. https://doi.org/10.1016/j.otc.2011.12.008

39. Stangerup SE, Tos M, Thomsen J, Caye-Thomasen P (2010) Hearing outcomes of vestibular schwannoma patients managed with 'wait and scan': predictive value of hearing level at diagnosis. J Laryngol Otol 124:490-494. https://doi.org/10.1017/S002221510 9992611

40 Stangerup SE, Tos M, Thomsen J, Caye-Thomasen P (2010) True incidence of vestibular schwannoma? Neurosurgery 67:13351340. https://doi.org/10.1227/NEU.0b013e3181f22660 (discussion 1340)

41. Taylor S, McCracken CF, Wilson KC, Copeland JR (1998) Extent and appropriateness of benzodiazepine use. Results from an elderly urban community. Br J Psychiatry 173:433-438. https:// doi.org/10.1192/bjp.173.5.433

42. Thurin E, Corell A, Gulati S, Smits A, Henriksson R, Bartek J Jr, Salvesen Ø, Jakola AS (2019) Return to work following meningioma surgery: a Swedish nationwide registry-based matched cohort study. Neuro-Oncology Practice. https://doi.org/10.1093/ nop/npz066

43. Thurin E, Rydén I, Skoglund T, Smits A, Gulati S, Hesselager G, Bartek J Jr, Henriksson R, Salvesen Ø, Jakola AS (2021) Impact of meningioma surgery on use of antiepileptic, antidepressant, and sedative drugs: a Swedish nationwide matched cohort study. Cancer Med. https://doi.org/10.1002/cam4.3868

44. Tos M, Stangerup S-E, Cayé-Thomasen P, Tos T, Thomsen J (2004) What is the real incidence of vestibular schwannoma? Arch Otolaryngol Head Neck Surg 130:216-220. https://doi.org/ 10.1001/archotol.130.2.216

45. van de Langenberg R, Hanssens PE, Verheul JB, van Overbeeke JJ, Nelemans PJ, Dohmen AJ, de Bondt BJ, Stokroos RJ (2011) Management of large vestibular schwannoma. Part II. Primary 
Gamma Knife surgery: radiological and clinical aspects. J Neurosurg 115:885-893. https://doi.org/10.3171/2011.6.JNS101963

46. Weaver MF (2015) Prescription sedative misuse and abuse. Yale J Biol Med 88:247-256

47. Wozniak MA, Kittner SJ, Price TR, Hebel JR, Sloan MA, Gardner JF (1999) Stroke location is not associated with return to work after first ischemic stroke. Stroke 30:2568-2573. https://doi.org/ 10.1161/01.STR.30.12.2568

48. Yang HC, Kano H, Awan NR, Lunsford LD, Niranjan A, Flickinger JC, Novotny J Jr, Bhatnagar JP, Kondziolka D (2013) Gamma knife radiosurgery for larger-volume vestibular schwannomas: clinical article. J Neurosurg 119(Suppl):801-807

49. Zeiler FA, Bigder M, Kaufmann A, McDonald PJ, Fewer D, Butler J, Schroeder G, West M (2013) Gamma knife radiosurgery for large vestibular schwannomas: a Canadian experience. Can J Neurol Sci 40:342-347

Publisher's note Springer Nature remains neutral with regard to jurisdictional claims in published maps and institutional affiliations.

Comments The microsurgical treatment of vestibular nerve schwannomas (VS) reached enormous progresses in the last decades.
Today, a multidisciplinary management is obligatory to minimize disabilities and to avoid morbidity secondary to treatment of these tumors. In this clear and well-written manuscript, the authors performed a nationwide registry-based study to assess the use of antidepressants and sedatives and the sick leave patients before and after vestibular schwannoma surgery. The results are very interesting: even if the Authors not compared VS surgery to other treatment forms such as observation or SRS, the use of antidepressants, sedatives, and the rate of sick leave was similar between VS patients and controls at the baseline preoperatively. However, two years after surgery, only $75 \%$ of patients were in full-time employment, compared to $88 \%$ of matched controls two years after surgery. Predictors for being on sick leave two years after surgery were sedative use at index date, more preoperative sick leave, and new-onset neurological deficits after surgery. As result, a multidisciplinary management is mandatory to minimize disabilities and to increase the quality of life and the early return to work.

Alex Alfieri,

Marc-Eric Halatsch,

Winterthur, Switzerland.

\section{Authors and Affiliations}

\section{Erik Thurin ${ }^{1,2}(1)$. Petter Förander ${ }^{3,4}$. Jiri Bartek $\mathrm{Jr}^{3,4,5}$. Sasha Gulati ${ }^{6,7}$. Isabelle Rydén ${ }^{1}$. Anja Smits ${ }^{1,8}$. Göran Hesselager $^{9} \cdot \varnothing_{\text {yvind Salvesen }}{ }^{10} \cdot$ Asgeir Store Jakola $^{1,6,11}$}

Petter Förander

petter.forander@sll.se

Jiri Bartek Jr

jiri.bartek@sll.se

Sasha Gulati

sasha.gulati@ntnu.no

Isabelle Rydén

isabelle.ryden@neuro.gu.se

Anja Smits

anja.smits@neuro.gu.se

Göran Hesselager

goran.hesselager@neuro.uu.se

Øyvind Salvesen

oyvind.salvesen@ntnu.no

Asgeir Store Jakola

jakola.asgeir@gu.se

1 Institute of Neuroscience and Physiology, University

of Gothenburg, Sahlgrenska Academy, Box 430,

40530 Gothenburg, Sweden

2 Department of Radiology, Sahlgrenska University Hospital, 41345 Gothenburg, Sweden
3 Department of Clinical Neuroscience, Karolinska Institute, 17176 Stockholm, Sweden

4 Department of Neurosurgery, Karolinska University Hospital, 17176 Stockholm, Sweden

5 Department of Neurosurgery, Rigshospitalet, Copenhagen, Denmark

6 Department of Neurosurgery, St., Olavs University Hospital HF, Postboks 3250 Torgarden, 7006 Trondheim, Norway

7 Department of Neuromedicine and Movement Science, Norwegian University of Science and Technology, Trondheim, Norway

8 Institute of Neuroscience, Neurology, Uppsala University Hospital, Uppsala, Sweden

9 Department of Neurosurgery, Uppsala University Hospital, Uppsala, Sweden

10 Department of Public Health and General Practice, Norwegian University of Science and Technology, Trondheim, Norway

11 Department of Neurosurgery, Sahlgrenska University Hospital, 413 46, Gothenburg, Sweden 